\title{
Kant, Guyer, and Tomasello on the Capacity to Recognize the Humanity of Others
}

\author{
Lucas Thorpe
}

Much has been written in the last few decades on the content of Kant's moral law, but relatively little on its scope. That is, there has been much discussion on how we should treat morally relevant others, but far less discussion of who or what we should count as morally relevant others. Before jumping into my argument let me say a few words on my terminology.

\section{A Few Remarks about Terminology}

Firstly, by "human" in the morally relevant sense I mean those who are demanding of moral respect in the Kantian sense. Some Kantians today, often worried about the moral status of non-human animals, make a distinction between different types of morally relevant others. On the one hand there are organisms that are free and rational and are deserving of moral respect and are members of the sphere of justice. On other hand there are non-rational sentient beings that are capable of feeling pain and are deserving of compassion and concern. Kant himself clearly rejects this distinction, as he thinks our duties toward non-human nature are indirect, being rooted in duties toward ourselves. I am open to such a distinction and think that there are parts of nature that demand a certain type of concern even though they do not demand respect. However, in this chapter, when I talk of "morally relevant others" or being "human" in the morally relevant sense I will mean those beings that are demanding of respect in the first sense. Such organisms are members of the sphere of justice and our relations toward them involve considerations of fairness and mutual respect. Commonly those who draw a line between rational and non-rational nature implicitly assume that this boundary corresponds to the division between language-using and non-linguistic organisms. The assumption being that rationality presupposes linguistic capacities. In this chapter, however, I will argue that the boundary cannot be defined in 
terms of the distinction between the linguistic and non-linguistic, and the account I offer leaves space for the possibility that there are non-linguistic beings that are deserving of respect in the Kantian sense.

Secondly, I often talk of "moral status attribution." By this I mean the judgment (which I think normally doesn't involve any inference) that a bit of the world around us is deserving of respect in the Kantian sense. By talking about "attribution" rather than "recognition" I mean to remain neutral about whether such attribution is justified or correct. As such, moral status attribution is something that can be studied empirically as part of a naturalistic science. The question of whether such attribution is justified or correct is a separate issue. When I am assuming that such attribution is correct, I will talk of "recognition" of the moral status of others.

Thirdly, as we shall see, Kant himself does not identify being "human" in the morally relevant sense with being a member of a particular biological species. Thus, being "human" in the moral sense is not to be identified with being biologically human. In order to avoid ambiguity, when I intend to talk about humanity in the moral sense I will use the word "human" in quotation marks. When I want to talk about being human in the biological sense I will use the word without inverted commas.

Finally, I do not often explicitly talk about freedom in this chapter. However, Kant himself identifies being "human" in the morally relevant sense with being free, in the sense of either being autonomous or having the capacity for autonomy. So this chapter could have been titled "recognizing freedom." Elsewhere I have argued that the capacity for autonomy should be identified with the capacity to be a member of a realm of ends. ${ }^{\mathrm{I}}$ In this chapter I develop this idea, appealing to recent work in developmental psychology and primatology, and suggest that this capacity for autonomy (the capacity to be a member of a realm of ends) can be understood in terms of the capacity to engage in shared cooperative activity. Hopefully my reasons for this should become clearer through the chapter.

\section{Introduction}

On the surface Kant himself seems quite clear about who is deserving of respect: The morally relevant others are all "rational, free beings" or all "human beings." It is clear, however, that Kant does not want to identify

I Thorpe 20II, 20IO, and 20I3. 
"human beings" in this sense with members of a particular biological species, for he is explicitly open to the idea that there might be nonbiologically human rational beings. Thus, for example he is explicitly open to the possibility of extraterrestrial rational beings, who would not be members of the same biological species as us, but who would, presumably be worthy of respect. ${ }^{2}$ And it would seem possible that there are members of our biological species who are not "human" in the morally relevant sense. For example, it is possible that Kant might think that some severely brain damaged biological human beings, and perhaps psychopaths, are not "human" in the morally relevant sense. Given these facts, a Kantian needs to give some account of how we are to recognize who or what counts as "human" in the morally relevant sense.

There are a number of distinct questions a Kantian faces when dealing with the question of what is involved in recognizing the "humanity" of others, and appealing to a concrete example may help clarify this issue. John is sitting on the chair in front of me. If I were to take the chair he was sitting on home and saw it in half, this might be a stupid thing to do; it might even be illegal, if I do not own the chair. There would, however, be nothing intrinsically wrong with the action. Sawing John in half, on the other hand, whatever I think of him, would not only be wrong, it would be reprehensible. Splitting the atom is fine, splitting John is not. But why? What's the difference? Kant's answer is that John is a different type of being from the chair, and a type of being that demands respect. Following Kant, I will name the type of being that John is "human" (in the morally relevant sense), a rational being, a moral subject or a person, and in this chapter I will treat these terms as co-extensional. ${ }^{3}$ Now, for Kant there is no (logical) contradiction involved in judging that the chair is a person and John is not. To respect the chair but not the person sitting on it would not be a theoretical mistake but a moral, practical one. If I decided to saw John in half I would not be making a theoretical mistake about his true nature, but would be doing something morally reprehensible.

\footnotetext{
2 Thus in his Anthropology from a Pragmatic Point of View he writes that, "The highest species concept may be that of a terrestrial rational being, however we will not be able to name its character because we have no knowledge of non-terrestrial rational beings that would enable us to indicate their characteristic property and so to characterize this terrestrial being among rational beings in general. It seems, therefore, that the problem of indicating the character of the human species is absolutely insoluble, because the solution would have to be made through experience by means of the comparison of two species of rational being, but experience does not offer us this" (Anth 7:322).

${ }^{3}$ Following Kant, I will use the term "human being" in a moral sense, allowing for the possibility that there are possibly some biological human beings who are not human in the moral sense and possibly some beings that are not biologically human that are human in the moral sense.
} 
We attribute a certain moral status to John but not to the chair, and this raises at least three questions:

(I) What is the content of this judgment? In other words, what is it to be "human" in the morally relevant sense?

(2) How do we, in fact, go about ascribing moral status to others?

(3) What, if anything, justifies this ascription?

This chapter has three main sections. In the first two, I examine Kant's answers to these three questions. In the final section I discuss recent work in developmental psychology that supports what I take to be the Kantian thesis that we have a natural capacity to recognize the humanity of others, and I suggest a reformulation of Kant's position in contemporary terms.

In terms of the first question, I will argue that to be "human" in the morally relevant sense is to have the capacity for morality, and that this involves: (a) the capacity to recognize others as ends rather than merely as means and (b) the capacity to enter into relations of ethical community with us.

In terms of the second and third questions, we need to remember that whenever we ask a "how do we know that p?" question we should be careful about the fact that this question contains two distinct questions: (I) The "how question." The answer to this can be a naturalistic, mechanistic, causal story. This has to do with how we go about making certain attributions. (2) The "epistemic question." The answer to this is essentially normative. This has to do with whether our attributions are justified. Our answers to the "how question" and the "epistemic question" may or may not be related. For example, in contemporary reliabilist accounts in epistemology the "how" and the "epistemic" questions are related; for reliabilists argue that if how we make an attribution is the result of a reliable process (and the attribution is true), then we know. So our answer to the question: "How do I know that John, but not the chair he is sitting on, deserves moral respect?" has two aspects: (I) How do we, in fact, go about making such moral status attributions? This seems to be an empirical question. (2) What (if anything) justifies such moral status attributions?

In a recent paper, Paul Guyer has suggested that our recognition of morally relevant others is based upon an argument from analogy. It is not clear whether he is offering this as an account both of how we go about attributing moral status to others and an account of what justifies such attribution, or whether this is merely meant to be an account of what justifies such attribution. I will assume, however, that his account is 
supposed to be an answer both to the how question and the justification question. And I will offer criticisms of it as an answer to both questions.

I will defend, in contrast, a version of what I call moral reliabilism. It is not clear that this is the position Kant himself took, as he does not himself offer a detailed account of what is involved in the recognition of the humanity of others, but I will argue this is the most plausible position for a contemporary Kantian ethicist to take. Moral reliabilism consists of two claims.

Firstly, there is the empirical, naturalistic claim that (a) we have a quasiperceptual capacity to directly ascribe moral status to various bits of the world around us. I will argue that this capacity is best thought of in Gibsonian terms as a capacity to pick up on certain types of social affordances; morally relevant others have the capacity to engage in ethical interaction with us, and recognizing the humanity of others involves picking up on this capacity. Those beings who are "human" in the morally relevant sense, then, afford interaction based on mutual respect. I will explain what I mean by this in more detail later in the chapter.

Secondly, there is the normative claim that, (b) we should assume as a postulate of practical reason that this capacity is reliable (although fallible). I suggest, then, that the most plausible story to tell here is that we have a natural (biological) capacity to recognize the humanity of others, and we must make a moral assumption that this capacity can reliably pick out the morally relevant bits of the phenomenal world around us. In Kantian terms we can think of the assumption that this natural capacity is normatively reliable as a postulate of practical reason. For our moral practice presupposes that we can reliably recognize morally relevant others, and so if morality is not to be an empty figment of our imagination we must assume (for moral, not theoretical reasons) that our capacity to identify which beings are deserving of respect is reliable.

At the heart of my position is a particular understanding of what it is to be "human" in the morally relevant sense. There has been much disagreement among Kant scholars as to what it is to be "human" in the morally relevant sense. Kant himself seems to identify being "human" with rational nature. But this has been interpreted in numerous ways. There are three main broad interpretations of what it is to be "human" in the morally relevant sense.

Firstly, some commentators, such as Christine Korsgaard and Allen Wood, identify "humanity" with the capacity for agency broadly understood. Thus, for example, Christine Korsgaard identifies "humanity" with the capacity to set ends arguing that, "[b]y 'humanity' Kant means the 
power of free rational choice, for 'the capacity to propose an end to oneself is the characteristic of humanity" (TL 6:392) (Korsgaard 1996a:346). Similarly, Allen Wood identifies "humanity" with the capacity to set and to systematize ends. Thus Wood argues,

The predisposition to humanity lies in between the predispositions to animality and personality. It encompasses all our rational capacities having no specific reference to morality. Put most generally, humanity is the capacity to set ends through reason... It enables us not only to set ends but to compare the ends we set and organize them into a system... Hence humanity also involves the capacity to form the idea of our happiness or well-being as a whole. (Wood I999: I I 8-19)

Secondly, many commentators stress that "humanity" essentially involves the capacity for morality. So, for example, John Rawls argues that,

Kant means by humanity those of our powers and capacities that characterize us as reasonable and rational persons who belong to the natural world... These powers include, first, those of moral personality, which make it possible for us to have a good will and a good moral character; and second, those capacities and skills to be developed by culture: by the arts and sciences and so forth. (Rawls 2000:188)

A similar position, stressing that "humanity" in the morally relevant sense involves our capacity for morality, is defended by, among others, Thomas E. Hill, Barbara Herman, and Onora O'Neill. ${ }^{4}$

Finally, Richard Dean has argued that "humanity" should be identified not merely with the capacity for morality, but with the possession of a good will. Thus he has argued that,

Humanity, in the sense of the humanity formulation, is indeed equivalent to some feature possessed by rational beings, but not by all minimally rational beings. Instead, "humanity" is Kant's name for the more fully rational nature that is only possessed by a being who actually accepts moral principles as providing sufficient reasons for action. The humanity that should be treated as an end in itself is a properly ordered will, which gives priority to moral considerations over self-interest. To employ Kant's terminology, the end in itself is a good will..$^{5}$

4 Thus, Thomas E. Hill (2002:77) argues that "Our humanity includes our capacity and disposition to follow the allegedly unconditional rational supreme principle of morality." And Onora O'Neill (1989:138) argues that "Rational beings presumably must be non-conditional values because they alone can will anything, hence they alone can have a good will." See also Herman 1993:238.

5 Dean 2006:6. See also Dean 2009:83-IOI. 
Although I have some sympathy for Richard Dean's account, in this chapter I will assume a version of the second position, namely that "humanity" in the morally relevant sense involves our capacity for morality. ${ }^{6}$ This capacity for morality can be understood as the capacity to interact with others on the basis of mutual respect, or as the capacity to become a member of a certain type of moral community (a realm of ends). I take these two characterizations to be extensionally equivalent. According to such a reading, it is only those bits of the phenomenal world that are capable of morality that demand moral respect. Now, many of those who defend such a reading take the first formulation of the categorical imperative as primary, and so suggest that it is only those beings that are capable of moral reasoning that are deserving of respect. Such a position, I believe, is overly intellectualist. One might think that only language-using creatures are capable of moral reasoning and so only such creatures are deserving of respect. In contrast, I defend a position that takes the second and third formulation of the categorical imperatives seriously and will argue that those beings which are deserving of respect are those who are (a) capable of recognizing others as ends and not merely as means and (b) capable of entering into relations of ethical community with us. On this approach it may turn out, as a contingent fact, that the only beings who are deserving of respect are those with linguistic capacities. But it is at least logically possible that there are creatures not capable of language which are capable of interaction based on mutual respect and of forming relations of ethical community with us. And in the final section of this chapter I will argue that there is evidence that pre-linguistic babies are such organisms, and that it is an open question whether there are non-human animals which have such capacities.

According to this position, there is no theoretical criterion we can apply to determine which individuals we are capable of forming such relations with, and so the only way to try and determine which individuals are deserving of respect is to try and form such relations with them. Recognizing the humanity of others is a matter of knowing how rather than knowing that.

Drawing on recent research in developmental psychology and primatology, especially the work of Tomasello and his associates, I will defend a

\footnotetext{
6 Epistemically the "capacity for morality" reading and the "good will" reading could be reconciled if we were to assume that every being that has a capacity for morality will ultimately realize this capacity, and so having the capacity for morality and being moral are equivalent. I think Kant sometimes flirts with such a position.
} 
modified version of what I take to be Kant's account. This research suggests that, unlike non-human animals, healthy human beings develop a capacity, between the ages of six months and two years, to engage in joint or shared cooperative activities. ${ }^{7}$ My suggestion is that what it is to be "human" (in a morally relevant sense) is to be a being we can engage in shared cooperative activities with. ${ }^{8}$ Tomasello and associates have suggested that it is this capacity that differentiates humans from non-human animals. ${ }^{9}$ Drawing on the work of Bratman (I989), they argue that joint cooperative activities have three essential characteristics:

(I) the interactants are mutually responsive to one another, (2) there is a shared goal in the sense that each participant has the goal the we (in mutual knowledge) do X together, and (3) the participants coordinate their plans of action and intentions some way down the hierarchy... the cognitive representation of the [joint] goal contains both self and other; that is, it contains not only the self s goal that the box be open, but also the self s goal that this be accomplished with the partner. (Tomasello, et al. 2005: 680)

And they provide evidence to show how this capacity slowly develops (and has its basis in simpler capacities) between the age of six months and two years. One thing Tomasello and his associates stress is that the capacity to engage in joint cooperative activities presupposes a capacity for joint attention, which they believe is not to be found in non-human animals. ${ }^{\text {Io }}$ And I will argue later in the chapter that joint attention itself should be

7 I will use "joint cooperative activity" and "shared cooperative activity" interchangeably. A joint cooperative activity is a shared cooperative activity involving only two individuals.

8 Elsewhere I argue that Kant's ethics should be understood as an "ethics of interaction," for the idea of a realm of ends is the idea of a community in which there is real interaction, and so, for Kant, to be moral is to strive to really interact with others. I am suggesting here that we should understand interaction in terms of engaging in joint cooperative activities.

9 Thus Moll and Tomasello, reporting on their own research, claim that although chimpanzees are "mutually responsive," "In none of the tasks did a chimpanzee ever make a communicative attempt to re-engage the partner... The absence of any efforts by the chimpanzees to re-engage their human partner is crucial: it shows that the chimpanzees did not cooperate in the true sense, since they had not formed a joint goal with the human. If they had been committed to a joint goal, then we would expect them, at least in some instances, to persist in trying to bring it about and in trying to keep the cooperation going. For humans the situation is different from very early on in ontogeny. [within I 8 months] when the adult stopped participating at a certain point during the activity, every child at least once produced a communicative attempt in order to re-engage him... [H] uman infants by the age of I 8 months, in contrast to apes, are able to jointly commit to a shared goal" (Moll and Tomasello 2007:64I).

Io Thus, Moll and Tomasello (2007:643) claim that although "apes do sometimes point for humans ... it seems that what the apes have learned from their experience with humans is that the human will help them, and that they can use the pointing gesture instrumentally in order to make him help them... However, no ape has ever been observed to point for another ape or for a human declaratively - that is, just for the sake of sharing attention to some outside entity, or to inform others of things cooperatively, as humans often do... [E]ven when they first begin to point 
thought of as a basic type of joint cooperative activity. They reach the (provisional) conclusion that it is this capacity that distinguishes human beings from non-human animals. ${ }^{\text {I }}$ This suggestion that only biologically human beings are capable of joint cooperative activity, however, has been controversial and many primatologists, especially those using more of an ethnographic methodology, believe that some non-human primates are capable of some forms of joint cooperative activity.

The capacity to engage in such shared cooperative activities involves both a motivational element and a cognitive element. In order to engage in shared cooperative activities, organisms must have the motivation to cooperate, and must also have various cognitive capacities, for example the capacities to represent shared goals, the capacity for role reversal, and the capacity for joint attention. Although Tomasello is engaged in a naturalistic project of explanation, I suggest that this account of what it is to be human corresponds to the Kantian understanding of what it is to be "human" in a morally relevant sense, and that the morally relevant others are those we can engage in joint cooperative activities with. ${ }^{\text {I2 }}$ It is interesting that Moll and Tomasello also suggest that the capacity to engage in joint cooperative activities lies at the heart of our moral capacities. Thus they claim that,

[p]erspectival cognitive representations and the understanding of beliefs also pave the way for what may be called, very generally, collective intentionality... That is, the essentially social nature of perspectival cognitive

at around I year of age, human infants do this with a full range of different motives, including the motive to share attention."

II "Although non-human animals may engage with one another in complex social interactions in which they know the goals of one another and exploit this, they are not motivated to create shared goals to which they are jointly committed in the same ways as humans" Moll and Tomasello (2007:682).

${ }^{\text {I2 }}$ I am not suggesting that we have no moral duties to those beings which we can't engage in joint cooperative activities with. Kant himself believes that we have no direct duties toward non-human animals, but rather that our duties to non-human animals are indirect, being based on a duty toward ourselves. His basic argument is that cruelty toward animals can cause us to become callous and that we have a duty toward ourselves not to be callous. Thus, Kant explains in the Metaphysics of Morals, that, "with regard to the animate but non-rational part of creation, violent and cruel treatment of animals is far more intimately opposed to a human being's duty to himself, and he has a duty to refrain from this; for it dulls his shared feeling of their suffering and so weakens and gradually uproots a natural predisposition that is very serviceable to morality in one's relationship with other people" (MS 6:443). I suggest a more plausible account would be to argue that there are two types of morally relevant others: those to whom we have duties of respect (which I have suggested consists of all those beings with which we can engage in joint cooperative activities with) and those toward which we have a duty of care (which would include at least most living beings, and perhaps all beings). In this chapter I have only concerned myself with morally relevant others understood in terms of those to whom we have duties of respect. 
representations enables children, later in the preschool period, to construct the generalized social norms that make possible the creation of socialinstitutional facts, such as money, marriage and government, whose reality is grounded totally in the collective practices and beliefs of a social group conceived generally... Importantly, when children internalize generalized collective conventions and norms and use them to regulate their own behaviour, this provides for a new kind of social rationality (morality) involving what Searle calls "desire-independent reasons for action." At this point, children have become norm following participants in institutional reality, that is to say, fully functioning members of their cultural group. (Moll and Tomasello 2007:646)

I have argued that Kant's ethics can be understood as an ethics of interaction, and my suggestion at the end of this chapter is that the best way of interpreting this in contemporary terms is to claim that the morally relevant others are those we are capable of engaging in joint cooperative activity with. If this is the case, then we have no criterion or principle to pick out which bits of the world are human in the morally relevant sense, for the only way we have of establishing whether a being is the sort we can engage in a joint cooperative activity with is to try and do so.

One way of thinking about this capacity to engage in shared cooperative activity is in terms of possessing certain types of social "affordances." The notion of an affordance was introduced by the ecological psychologist J. J. Gibson. Gibson argues that affordances are to be understood in terms of the possibilities of action that the environment offers an organism, and he argues that in perception organisms are able to directly pick up on such affordances. On the account I am proposing, being "human" in the morally relevant sense is to be understood in terms of the possession of certain types of social affordance. Such social affordances are not to be understood in terms of the possibility of action offered by an object or environmental feature, but in terms of the possibility of interaction offered by another organism. Morally relevant others have the capacity to interact with us in a cooperative way, such that we are able to engage in shared cooperative activities with them. To recognize the "humanity" of others is to pick up on this possibility of interaction. Gibson explains the notion of an affordance in the following terms:

The affordances of the environment are what it offers the animal, what it provides or furnishes, either for good or ill. The verb to afford is found in the dictionary, but the noun affordance is not. I have made it up. I mean by it something that refers to both the environment and the animal in a way that no existing term does... If a terrestrial surface is nearly horizontal 
(instead of slanted), nearly flat (instead of convex or concave), and sufficiently extended (relative to the size of the animal) and if its substance is rigid (relative to the weight of the animal), then the surface affords support. It is a surface of support, and we call it a substratum, ground, or floor. It is stand-on-able, permitting an upright posture for quadrupeds and bipeds. It is therefore walk-on-able and run-over-able. It is not sink-into-able like a surface of water or a swamp, that is, not for heavy terrestrial animals. Support for water bugs is different... Note that the four properties listed horizontal, flat, extended, and rigid - would be physical properties of a surface if they were measured with the scales and standard units used in physics. As an affordance of support for a species of animal, however, they have to be measured relative to the animal. (Gibson 2015: I19)

Affordances, then, are the possibilities of action an environment offers an organism. Thus, for example, a pathway through a cluttered environment is an affordance as it allows for locomotion between two points. An opening in a horizontal surface, such as a doorway, is also an affordance in that it offers the possibility of passing-through. Now, I suggest that there are social affordances. These should be understood not in terms of the possibility of action, but in terms of the possibility of interaction.

Now, even non-human primates are able to pick up on some social affordances. For example, chimpanzees are able to recognize a hand-raise signal as an invitation to play. ${ }^{13}$ In so doing, chimpanzees are able to recognize certain possibilities of interaction. Now, I suggest that organisms that are "human" in the morally relevant sense possess the capacity to engage in certain types of interaction with us: namely, interaction that involves mutual respect and allows for shared cooperative activity. Thus, our capacity to recognize the "humanity" of others involves the capacity to pick up on the possibility of such interaction. To be "human" is to invite others to interact on the basis of mutual respect, and to recognize the "humanity" is to pick up on such an invitation.

The account I am offering has an essentially first person plural starting point: To pick up on the humanity of others is to implicitly recognize the

13 Tomasello (2008:23) explains how chimpanzees develop this capacity to pick up on a hand-raise as an invitation to play in the following terms:

(i) initially one youngster approaches another with rough-and-tumble play in mind, raises his arm in preparation to play-hit the other, and then actually hits, jumps on, and begins playing;

(ii) over repeated instances, the recipient learns to anticipate this sequence on the basis of the initial arm-raise alone, and so begins to play upon perceiving this initial step; and

(iii) the communicator eventually learns to anticipate this anticipation, and so raises his arm, monitors the recipient, and waits for her to react - expecting this arm-raise to initiate the play. 
possibility of becoming a "we." In contrast, Guyer's account, which will be examined later in the chapter, has an essentially first person singular starting point. According to Guyer, I start by recognizing my own moral status, and then judge that others are demanding of moral respect because they are relevantly similar to me. ${ }^{\mathrm{I}}$

The reason I think that this implies that there is no theoretical criterion to decide whether another bit of the world is "human" in the morally relevant sense is because, following Gibson, I think there is a clear difference between picking up on an affordance, on the one hand, and classifying or labeling an object on the other. To pick up on an affordance involves a type of know-how, rather than classifying an object theoretically; it involves knowing how an object can be used or interacted with. As Gibson explains,

The theory of affordances rescues us from the philosophical muddle of assuming fixed classes of objects, each defined by its common features and then given a name. As Ludwig Wittgenstein knew, you cannot specify the necessary and sufficient features of the class of things to which a name is given. They have only a "family resemblance." But this does not mean you cannot learn how to use things and perceive their uses. You do not have to classify and label things in order to perceive what they afford. (Gibson 2015:126)

Learning how we can interact with various bits of the world involves trying to interact and learning which bits of the world allow for what types of interaction. This involves a practical rather than a theoretical capacity. It involves knowing-how rather than knowing-that. Those bits of

I4 It is interesting to note that although many followers of John Rawls also seem to have an essentially first person singular starting point, there is a way in which Rawls himself also starts with the "we." For Rawls himself is clear that the question of justice has to do with the distribution of the social product and his starting point is the idea that "society is a cooperative venture for mutual advantage." Thus, Rawls's theory takes as its starting point the fact that those in the sphere of justice are engaged in some sort of shared collective cooperative activity. Rawls's theory of justice has to do with how to share the benefits and burdens of social cooperation, and so the sphere of justice presupposes a background of shared cooperative activity. Thus, he argues that the principles of social justice "provide a way of assigning rights and duties in the basic institutions of society and they define the appropriate distribution of the benefits and burdens of social cooperation" (Rawls I 999:4). This stress on the sharing of the collective social product is central to Rawls's account, thus he points out that, "In a well-ordered society individuals acquire claims to a share of the social product by doing certain things encouraged by the existing arrangements. The legitimate expectations that arise are the other side, so to speak, of the principle of fairness and the natural duty of justice. For in the way that one has a duty to uphold just arrangements, and an obligation to do one's part when one has accepted a position in them, so a person who has complied with the scheme and done his share has a right to be treated accordingly by others. They are bound to meet his legitimate expectations" (275). 
the phenomenal world that are "human" in the morally relevant sense are those bits of the world that we can interact with on the basis of mutual respect. And learning how to recognize which bits of the world are "human" in the morally relevant sense involves picking up on how we are able to interact with various bits of the world; we can only learn which parts of the world we can interact with morally by trying to so interact, and being open to the possibility of such interaction.

The account I am suggesting has two implications that Kant himself may not have accepted. Firstly, it suggests that it is an open question as to whether there are non-biologically-human animals that are "human" in the moral sense. Secondly, it suggests that being "human" in the morally relevant sense may be something that comes in degrees rather than being an either-or matter. The reason for this is because there are many different types of collaborative activity differing in complexity, and there are individuals that are capable of engaging in certain types of collaborative activities but not in others. For example, some severely autistic adults are not able to engage in those cooperative activates that involve language. But they may have the capacity to engage in other types of cooperative activities. Although Kant himself may not have accepted these claims, I believe that contemporary Kantian ethicists should welcome these positions.

\section{Recognizing Humanity}

In the previous section of this chapter I argued that, for Kant, the morally relevant others are those capable of morality, and I have suggested that this should be understood in terms of the capacity to engage in shared cooperative activity. In this section I will examine what, if anything, justifies our judgment that a bit of the world has the capacity to be moral. There would seem to be at least four possible options here. The first three would provide me with some theoretical justification for my belief that John is a human being in a morally relevant sense, the fourth denies such a theoretical justification is possible. In this chapter I will defend this final option. The four options are:

(a) That there is some theoretical criterion we can use to distinguish between what falls under the concept "moral subject" and what does not. In Kantian terminology this would imply that the concept "moral subject" could be schematized (and that some sort of theoretical deduction of the objective reality of this concept could be given). 
However, it seems clear that for Kant such an account is a nonstarter, and so I will not discuss this option any further in this chapter.

(b) Inference to the best/only explanation. ${ }^{\text {Is }}$

(c) An argument from Analogy. I am justified in believing that I am a moral subject and John is relevantly like me whereas the chair is not. This is the argument suggested by Paul Guyer in a recent paper (Guyer 2013).

(d) There is no theoretical justification of my judgment that John is a moral subject, so we must assume, as a postulate of practical reason, that we have a non-theoretical but reliable capacity to recognize other morally relevant subjects (and certain things, such as language, works of art, etc., as the product of such subjects).

In this section I will focus on the final two possibilities. I will argue that the final option is more plausible, both as an interpretation of Kant and as an ethical position, than Guyer's position. If I am right, then my judgment that John is an end in himself has no theoretical justification, not even a probable one. Although I will focus on arguing against Guyer's position, I believe that most of my arguments against the argument from analogy will also be telling against justifications that appeal to inference to the best explanation.

Guyer begins his paper by examining Kant's argument that I am (practically) justified in judging myself to be free from the first-person perspective, and rightly notes that such an argument cannot be used from the third-person perspective to judge that another person is a free moral subject. ${ }^{16}$ This seems to be a problem for Kant for, as Guyer asks, "if I can prove myself to be free and subject to the moral law, but if others are due moral treatment from me only because they are free and rational beings who are ends in themselves, how can I prove to myself that others are indeed ends in themselves who must always be treated as such and never merely as means?" (Guyer 2016: I 58) Guyer's solution is to suggest that

is Kant suggests such an account at the end of the Critique of Judgment. Here he writes, "If I determine the causality of the human being with regard to certain products that are explicable only by means of intentional purposiveness by thinking of it as an understanding, I do not have to stop there, but can attribute this predicate to him as a well-known property, and I have cognition of him by this means" (5:484). This is the only place I know of where Kant makes such a suggestion.

16 "What Kant now offers are arguments by means of which each of us may prove him- or herself free, but not arguments by means of which any of us can prove that any or all others are free. Kant's arguments address the first-person question of how I should choose to behave, not the third-person question of whether I can hold others responsible for their actions" (Guyer 2016:153). 
our belief that others are free moral subjects can be justified by an argument from analogy. Thus he argues that,

Kant never explicitly asks whether one can know that other human beings actually possess free wills or attempts to prove it, presumably taking it to be obvious to each of us that other human beings ${ }^{17}$ (and nothing else) are actually rational beings. Yet it is clear that on Kant's premises we can be directly acquainted only with the outward appearances of other persons, and cannot have any immediate knowledge of their inner states, let alone of the noumenal reality behind that. So the attribution of any inner states at all to others must presumably be based on analogy with our experience of our own inner states, mediated by our assumptions about the connections between our own states of inner sense and our own outwardly observable bodily states. (Guyer 2016:156, my emphasis)

Now, as Guyer notes, Kant is committed to the view that analogical arguments can only provide us with probability and never certainty, and so he suggests that our belief in the existence of other subjects can at most be "highly probable but not certain" and perhaps must ultimately be based on "some sort of moral Pascalian wager." ${ }^{8}$ Now, rather than thinking of this as posing a problem Guyer suggests that, "uncertainty about the real freedom of others could lead us to temper our retributive instincts with humility and mercy... leaving us to be rigorous in our moral demands on ourselves but merciful in our judgments about others" (Guyer 2016: I60).

Now, there is some textual evidence that Kant appeals to some form of the argument from analogy in his empirical psychology. Thus, he suggests in his Anthropology from a Pragmatic Point of View that a proper knowledge of human nature needs to start from a first person singular point of view, namely with introspection (inner experience). Thus Kant argues that,

[k]nowledge of the human being through inner experience, because to a large extent one also judges others according to it, is more important than correct judgment of others, but nevertheless at the same time perhaps more difficult... So it is advisable and even necessary to begin with observed appearances in oneself, and then to progress above all to the assertion of certain propositions that concern human nature; that is to inner experience. (Anth 7:143)

${ }^{17}$ And here Guyer seems to mean "human beings" in the first sense of being a member of the biological species.

18 "[T]he value of treating others morally if they really are free and rational beings is so high, and the error of failing to treat them morally if they really are the kinds of beings who should be morally treated would be so grave, that even just a probability - or indeed just the possibility - that the other human bodies I observe and interact with are really also bearers of moral personality is enough to make it rational to treat them as if they are" (Guyer 2016:159). 
And in his lectures he explicitly appeals to the argument from analogy, arguing that,

I consider thinking beings ... through experience, which happens in part internally in myself, or externally, where I perceive other natures, and cognize according to the analogy that they have with me; and that is empirical psychology, where I consider thinking natures through experience. (V-Anth 28:224)

These passages, however, are about the proper method of empirical psychology and do not obviously concern moral status attribution. There is no good reason to think that the proper methodology for predicting and explaining the behavior of others should also provide an account or justification of how we recognize which bits of the world around us are deserving of moral respect. So, the fact that Kant suggests a first person singular starting point and appeals to the argument for analogy in his empirical psychology should not be taken as evidence that his account of moral status attribution should also be thought of as appealing to an argument from analogy. In addition, there has been some debate, even with regard to his empirical psychology, of whether Kant really is committed to taking introspection as his starting point. ${ }^{19}$

As we have seen, Guyer suggests that Kant thinks that my belief that John is a moral subject can only be justified by an argument from analogy. I believe, however, that there is an alternative explanation that is both morally more plausible and Kantian in spirit, namely that such beliefs cannot and do not need to be justified theoretically. Instead I assume that I have a reliable but non-theoretical capacity to immediately ascribe moral status to others and although we cannot know theoretically that this capacity is reliable we must assume for moral reasons (as a postulate of practical reason) that this capacity is reliable, in that it is capable of reliably picking out those parts of the phenomenal world that are demanding of respect. Kant himself seems committed to the view that certain capacities

I9 Thus, for example, Thomas Sturm has argued that for Kant the proper starting point of empirical psychology is not introspection but the observation of the external actions of ourselves and others. Thus, he argues that from "at least the 178 os on, [Kant] advances a methodological claim against introspection as the primary method of knowing the human mind. He claims that one can experience "the state of one's own mind ... through attention to one's own actions just as well" (Sturm 200I:I74), and he continues to claim that, "[o]ur vocabulary of representations, thoughts, feelings, passions, traits of personal character, and so on, is intimately connected to a careful observation of human action and human life as it occurs and as it can be observed, especially in society (7:1 19-20). 'Psychological phenomena' are open to public observation in Kant's view, contrary to what Nayak and Sotnak and others have claimed” (I75). Sturm's Interpretation has been forcefully criticized by Patrick R. Frierson (2014:4-9). 
are necessary (albeit subjective) conditions of morality. He makes this clear in the Metaphysics of Morals where he argues that, "[t]here are certain moral endowments such that anyone lacking them could have no duty to acquire them. - they are moral feeling, conscience, love of one's neighbor and respect for oneself (self-esteem). There is no obligation to have these because they lie at the basis of morality, as subjective conditions of receptiveness to the concept of duty... All of them are natural predispositions of the mind..." (TL 6:399). I suggest that our capacity to recognize the humanity of others should be thought of as one of the aesthetic presuppositions of morality. Indeed, the natural predisposition to love one's neighbor presumably involves a capacity to recognize one's neighbor.

This capacity is manifested in our capacity to immediately recognize noise as meaningful speech, to hear a scream as a cry for help. I think that thinking of this moral capacity to recognize others in terms of hearing is very Kantian in spirit, as much of the vocabulary Kant uses when talking of reason and understanding has to do with hearing. For example, the main activity of understanding is bestimmen (to determine) which, of course, has the root stimme (voice). And as Allen Wood points out, "Kant's German word for 'reason' (Vernunft) is derived from the verb vernehmen, which means to hear, and more specifically to understand what you hear." I suggest then that ultimately, for Kant, a rational being or moral subject is something that has a voice (and so can make moral demands) and can listen (vernehmen) to the moral demands of others. ${ }^{2 \mathrm{I}}$ It can make demands and understand the demands of others. And I believe that this capacity to understand (vernehmen) the voice of the other is immediate. To argue that there is some sort of (unconscious?) argument from analogy going on here does not fit in with our moral phenomenology. I don't think that I hear the baby scream and quickly and unconsciously think that the baby is like me and so its crying must be a call for help, but instead I believe that I just immediately hear the screams of the child as a cry for help, as a moral demand. And Kant believes that such demands are irresistible. ${ }^{22}$ If I do not

20 Wood 2008: I 8.

${ }^{21}$ I believe that this is what Kant is getting at in the Opus Postumum, where he repeatedly defines the human being as a being with both rights and duties. (Here he opposes the human being to God who is a being with only rights).

22 Although his moral ear may have been closed to the cries of babies (and the singing of prisoners): "A child that comes into the world apart from marriage is born outside the law (for the law is marriage) and therefore outside the protection of the law. It has, as it were, stolen into the commonwealth (like contraband merchandise), so that the commonwealth can ignore its existence (since it was not right that it should have come to exist this way), and can therefore also ignore its annihilation" (MM 6:336). No one is perfect. 
block my moral ear and If do not drown out the cry for help with other voices I cannot but help to react to it. ${ }^{23}$ This capacity to make and recognize demands of others, is at the heart of what it is to be "human" in the morally relevant sense. Now, I suggested that this capacity can be thought of in terms of having a "voice," but I think that having such a voice does not necessarily require natural language. For, as we shall see, pre-linguistic young babies are capable of making and recognizing such demands. And perhaps some members of other species are too.

I believe such an account is more plausible ethically than Guyer's account. Explaining our belief in the existence of other moral subjects as resting on probabilistic reasoning also does a bad job of explaining evil acts. ${ }^{24}$ I think that the Nazi who refuses to see the Jew in front of him as a human being is not making a bad analogical inference, but is refusing to recognize the humanity of the person suffering in front of him. He is refusing to hear the scream as a cry for help. Doing bad things to other people is often very difficult. ${ }^{25}$ Thus, John Doris points out that "The Einsatzgruppen shot thousands of jews in the back of the neck, one by one, so there was very close contact with the victims. They were apparently expected to work for only an hour at a time, despite the fact that this task was not physically demanding, and they were liberally provided with alcohol" (Doris 2002: 56). Christopher Browning makes clear in his book based upon the reports of members of a German police unit that was given the order to massacre Jews in Poland, shutting out the voices and demands

${ }^{23}$ For a fuller account of the irresistibility of the voice of conscience, see my paper "The Point of Studying Ethics According to Kant” (Thorpe: 2006). See also Sticker 2017.

24 And I believe that for Kant, evil acts can be done by good people. I think this is true even in the case for Nazis. This belief is, in part, based upon my experience as a tour guide in Europe. I sometimes gave "Holocaust Tours" and we sometimes organized meetings with ex-members of the Hitler youth who were fervent Nazis in their youth and now met with groups of mainly Jewish visitors at the Wansee Conference house, where the decision on the "final solution" was made. These ex-members of the Hitler youth were rabidly anti-Semitic (and evil?) in their teens, but the judgment of most of the participants at the meeting were that they were good people (now).

25 Thus, for example, in his discussion of the Milgram experiments, where subjects were showed a remarkable willingness to administer seemingly painful shocks to a confederate of the experimenter, John Doris argues that, "the most striking feature of the demonstration is not blind obedience but conflicted obedience. Horribly conflicted obedience: Subjects were often observed to 'sweat, tremble, stutter, bite their lips, groan and dig their fingernails into their flesh' (Milgram).” And he suggests that historical studies, especially of the Holocaust, suggest that such conflict was not merely a result of the experimental circumstances (Doris 2002:42-3). The quote from Milgram is from $1963: 375$. 
of the victims was very difficult indeed, at least for most of the perpetrators. ${ }^{26}$ Now, the Nazis made numerous films that were made for the purpose of convincing viewers that certain groups, such as Jews and the physically and mentally disabled, were not really human and their lives were "not worth living." Some of these films were made specifically to "help" the perpetrators deal with their "difficult work." ${ }^{27}$ But even for most of those committed to the ideology, killing was not easy. Surely an argument from analogy is not that hard to shut off?

Finally, I disagree with Guyer's suggestion that our uncertainty about the moral status of other human bodies around us as free moral subjects could be the basis for us "to temper our retributive instincts with humility and mercy" (Guyer 2016:160). If a person does something morally wrong, surely to doubt their status as a moral subject will not lead us to humility and mercy but may instead lead us to think of them as rabid dogs. Yes, it may remove our retributive instincts, for one does not punish a rabid dog, but I am not sure that such doubt will lead to moral compassion. As an alternative I suggest that, for Kant our attitude of humility and mercy, the need to treat ourselves harshly and others gently for our and their moral failings, is not based on a skepticism about whether or not the person in front of us is a free moral subject but on a skepticism about whether the evil acts of others are really an indication that they do not actually have good wills. ${ }^{28}$ When confronted by evil or bad acts we may be tempted to believe that the individual that committed these acts has an evil will. The skepticism that leads to compassion and humility is one that doubts whether such acts are an indication of a bad will. A skepticism that does not doubt the voice of our moral ear that tells us that the body in front of us is a human being and demanding of respect, but doubts that their evil actions are really a manifestation of an evil will. The fact that a virtuous agent can do appalling things is, I believe, central to Kantian ethics. For a virtuous person is not, for Kant, someone who has a perfect or holy will, but is instead someone who is striving for such moral perfection. As such, a

26 Browning 1992. It is based on the same documentary evidence that Daniel Goldhagen used for his later and unfortunately better known book Hitler's Willing Executioners (1996), and reaches a very different, and in my eyes, a far more plausible conclusion.

27 One of these films is called "A life not worth living" and was made to be shown to doctors involved in the "Euthanasia" program against the physically and mentally disabled.

28 Thus Kant explains that, "Now through experience we can indeed notice unlawful actions, and also notice (at least within ourselves) that they are consciously contrary to law. But we cannot observe maxims, we cannot do so unproblematically even within ourselves; hence the judgment that an agent is an evil human being cannot reliably be based on experience" ( $R G V$ 6:20). Similar passages are not hard to find. 
virtuous person is someone who slowly converges on holiness over time, who over their life slowly gives in to the temptation of listening to their conscience and the moral demands of others. Now, such a process may involve a long series of two steps forward and one step back. But if we think that having a good will does not consist in always doing the right things, but in terms of having a phenomenal character that slowly converges on doing the right thing (gladly), then we can always be skeptical about whether a particular bad act, or any finite series of bad acts, is necessarily the manifestation of a vicious character. We can always be forgiving, merciful, and humble because we can always tell ourselves that we do not know where in their life the seemingly vicious person in front of us is. For all we know they may be in the middle of a step back rather than two steps forward. At least for me, this fits with my moral intuitions. If, for example, I catch a student plagiarizing and decide to be merciful, this is not because I think "maybe she is not free, maybe she is just a machine that has been programmed by the society around her," but because I think "she is young, she will grow older and hopefully better."

\section{The Capacity to Recognize Humanity and Recent Research in Developmental Psychology}

Up until this point in the chapter I have been primarily interested in defending an interpretation of Kant's position. I have argued that Kant believes that we have no criterion of principle for judging which bits of the world around us are human in the morally relevant sense, but that a Kantian should assume as a postulate of practical reason that we possess a reliable capacity to recognize the humanity of others. In this final section, drawing on recent research in developmental psychology, I will briefly suggest a more sophisticated naturalistic version of this thesis. This research suggests that we are born with an innate capacity to recognize other human beings, and in particular to distinguish between human faces and other images and between human voices and other sounds, ${ }^{29}$ and that at a very early age humans, unlike non-human animals, begin to develop a capacity to engage in joint cooperative activity. ${ }^{30}$ And I have argued that

29 As Janet Wayne Astington argues, "Looking at faces, listening to voices, babies seem tuned into people right from the start. They are born that way. . . It is not that all their understanding is innate but that they have innate predispositions and these help them to distinguish one person from another and from other things in the world" (Astington 1993:38).

30 And this research suggests that the capacity to engage in joint cooperative activities presupposes a capacity for sophisticated joint attention (which also seems to be a capacity lacking in all other 
what it is to be human (in a morally relevant sense) is to be a being we can engage in shared cooperative activities with. ${ }^{3 \mathrm{I}}$ If this is the case, then we have no criterion or principle to pick out which bits of the world are human in the morally relevant sense, for the only way we have of establishing whether a being is the sort we can engage in a joint cooperative activity with is to try and do so. If the conclusions of this research are correct then the more sophisticated version of my thesis is, the capacity to recognize other human beings is either innate or develops over the first two years after birth and that, as a postulate of practical reason, we must assume that this natural capacity is able to reliably pick out human beings in a morally relevant sense.

Although the seemingly innate capacity to recognize faces and distinguish between voices and other sounds is obviously not a capacity to recognize human beings in a morally relevant sense, it seems likely that such capacities are at the basis of the more complex capacity to engage in joint cooperative activity that seems to develop slowly between the ages of six months and two years - the capacity to engage in joint cooperative activities. I believe that this capacity does lie at the heart of our capacity to recognize morally relevant others, as, for a Kantian, the morally relevant others are those we can engage in joint cooperative activities with. In the previous section of this chapter I criticized Guyer's reading of Kant. Guyer suggested that Kant's position that our judgment that someone or something is a morally relevant other is based on an argument from analogy. I criticized this as a reading of Kant. In this section I will argue that even if this were a correct reading of Kant, contemporary research would suggest that it is false, for our capacity to engage in joint cooperative activities clearly seems to develop before we develop (and hence does not depend on) the capacity to engage in complex analogical reasoning.

Starting in the I920s Jean Piaget, basing his research on the verbal responses of young children, reached the conclusion that young children cannot distinguish between people and things nor between thoughts and things. This remained the orthodoxy for many decades. More recent research, however, using different techniques, primarily the habituation/

non-human animals) and that in healthy infants this capacity for joint attention uses the innate capacities to recognize faces and to distinguish between voices and other sounds.

3r Elsewhere I argue that Kant's ethics should be understood as an "ethics of interaction," for the idea of a realm of ends is the idea of a community in which there is real interaction, and so, for Kant, to be moral is to strive to really interact with others. I am suggesting here that we should understand interaction in terms of engaging in joint cooperative activities. 
dishabituation methodology, has suggested that Piaget's findings were false. ${ }^{32}$ Recent studies suggest that even in the first months, and probably even hours, young babies seem to have the capacity to distinguish between people and things. In particular, these studies seem to show a discriminating response between human faces and voices on the one hand, and nonhuman patterns and noises on the other.

Facial recognition in young infants. Astington, writing in 1993, explains that, "although some researchers have found that two-month-olds prefer a face over other patterns of equal complexity, generally this work has shown that babies don't reliably show this preference until four or five months of age. However, research using real faces, which are moving and three-dimensional as well as having contrast and complexity, has shown that much younger infants, even those two or three days old, can discriminate between their mothers face and that of a stranger" (Astington I 993: 38).

More recent research seems to suggest that the capacity to distinguish faces from other patterns is present from birth. Thus Bushnell, in a $200 \mathrm{I}$ study, writes that "There is no doubt that the human infant is capable of face discrimination and face recognition within a surprisingly short time after birth" (Bushnell 2001:67) and provides evidence from an experiment on 29 newborns that within 72 hours of birth young infants are able to remember their mothers' faces. ${ }^{33}$ Mondloch et al. (1999) provide evidence that six-week-old infants have a marked visual preference for the human face. In addition, young infants are able to distinguish between human faces and faces of other species (De Haan et al. 2002). There is even evidence to suggest that babies as young as four months discriminate between attractive and unattractive faces (Samuels et al. 1994). One interesting result suggested by Pascalis, Haan, and Nelson is that the human capacity to recognize faces is generic but begins to narrow after about three months, "becoming more human face specific" (Pascalis et al. 2002). This study suggests that young infants (six months) are actually better at distinguishing between the faces of individual monkeys than

32 Astington quite clearly explains this methodology in the following terms: "We keep showing her the same things time and time again until she is bored with it and doesn't look at it for very long; she is habituated to it. Then we show her something different. Does she spend longer looking at the new thing or does she seem bored with it as the one she has seen repeatedly? If she spends longer, that is, if she dishabituates, we know it seems different to her from what she was looking at before" (Astington I993:39).

33 The evidence of this experiment suggests that even within the first three days of birth "an increased opportunity to view the mother's face is associated with stronger visual preference levels" (Bushnell 200I:70). 
slightly older infants (nine months). In this study, six-month-old infants, nine-month-old infants, and adults were shown pictures of both monkey and human faces, and only the youngest group showed signs of discrimination between individuals of both species. That is, six-month-olds showed signs of discriminating between monkey Bob and monkey Bill. Ninemonth-olds and adults did not.

The capacity to distinguish between voices and other sounds in very young infants. Astington writes that, "(n)ewborns can also distinguish their mother's voice from that of someone else. They are startled by sudden noises and soothed by rhythmic music, but it is human voices they really seem to listen to. A crying baby may stop crying when he hears his mother's voice; another baby, lying quietly, may start to kick excitedly when her father starts to talk to her" (Astington 1993:38).

Once again, Ashington's claims seem to be confirmed by recent experimental evidence. For example, in a classic study of four-day-old French infants, Mahler et al. have shown that four-day-old infants "distinguish utterance in their native language from those of another language" (Mehler et al. 2002:25). And in a recent study, Vouloumanos and Werker argue that "humans are born with a preference for listening to speech" and cite recent studies that seem to show that newborn infants are "sensitive to word boundaries, distinguish between rhythmically dissimilar languages, distinguish between stress patterns of multisyllabic words, categorically discriminate lexical versus grammatical words and differentiate between good and poor syllable forms." ${ }^{34}$ There is a great amount of additional research that suggests that the capacity to distinguish between the human and the non-human, in very sophisticated ways, is found at a very early age. ${ }^{35}$

Now, of course, these seemingly innate capacities to recognize faces and distinguish between speech and other sounds are not themselves capacities to recognize the humanity of others in any moral sense. However, I suggest

34 Vouloumanos et al. 2007:I 59. Worried that past studies may have only showed a preference for speech over white noise, in their study Vouloumanos and Werker show that newborns discriminate between speech and "complex non-speech analogues" that "were modeled on sine-wave analogues of speech" ( 160$)$.

35 For example, Tomasello claims that "Infants recognize self-produced, biological motion within a few months after birth, and they soon turn to look in the same direction as other persons as well. By around six months of age, infants have developed sufficient expectations about human animate actions to be able to predict what others will do in familiar situations. Thus, for example, using habituation methodology, Woodward found that infants of this age expect people (specifically, human hands) to do such things as reach for objects they were just reaching for previously. Infants do not expect inanimate objects that resemble human hands (e.g., a garden-tool claw) to 'reach' toward the familiar object in similar circumstances" (2005:678). 
that, in healthy infants, these basic innate capacities play a role in the more complex capacity to engage in joint cooperative activity, and I argue that this capacity lies at the heart of our capacity to recognize the humanity of others in a moral sense. ${ }^{36}$

The capacity to engage in shared cooperative activity and declarative pointing. The previous two capacities do not, in themselves, seem to be moral capacities, although they probably play a role in the genesis and development of the fully moral capacities. I have suggested that a central role in the development of moral capacities is played by the capacity to engage in joint cooperative activity. One aspect of our capacity to recognize the humanity of others has to do with declarative pointing, and our capacity to recognize such pointing as an invitation to look. Declarative pointing, which seems to be uniquely human, is pointing "for the sake of sharing attention to some outside entity, or to inform others of things cooperatively, as humans often do" (Moll and Tomasello 2007: 643). Such pointing can be understood as an invitation to look, and I have argued that recognizing such activity is best thought of as picking up on a social affordance, that is picking up on the possibility of a certain type of interaction. One reason why I feel it is important to discuss the capacity of declarative pointing is because this is a capacity to initiate a certain type of collaborative activity that seems to develop before human infants develop linguistic capacities. Given the fact that I have suggested "humanity" in the morally relevant sense should be identified with the capacity to engage in joint or shared cooperative activities, the facts I will discuss subsequently suggest that being "human" should not be identified with the possession of linguistic capacities. I will follow the account of the development of the capacity to point and engage in shared cooperative activity as offered by Michael Tomasello and his team. And it should be pointed out that his account is quite conservative in that it suggests a quite late development of these capacities in the normally developing human infant. Other researchers, such as Vasudevi Reddy have suggested that the capacity to engage in shared cooperative activity emerges much earlier in infant development and is, for example, manifested in the dyadic sharing

${ }^{36}$ Now, of course, such capacities will not be singularly necessary for the development of the capacity to recognize humanity (in a moral sense), for obviously blind and deaf individuals are capable of morality, but taken together a child who was born without any innate capacity to distinguish sensitively between the human and non-human might not be able to develop such a capacity. In addition, sociopaths, if there are any, are presumably born with these capacities, and so these capacities will not be sufficient. But my suggestion is that such innate capacities probably play a role in the development of our moral capacity. 
of emotions between mothers and their babies (see Reddy 2010). I am sympathetic to Reddy's account, but for my purposes, the important point to establish is that this capacity develops before the development of linguistic abilities. And even on a conservative account of the developmental sequence, such as Tomasello's, the capacity to initiate joint cooperative activities through pointing develops prior to the development of linguistic capacities. Indeed, Tomasello himself believes that these pre-linguistic capacities are what make the development of linguistic capacities possible as the semantic character of language essentially involves reference, and our capacity to refer is rooted in our capacity for joint attention and pointing. And so the possession of these capacities is a necessary condition for the development of language.

Declarative pointing is a complex activity and presupposes a number of other capacities. Pointing in normally developing human infants begins in the months around the first birthday, prior to the emergence of linguistic abilities (Tomasello 2008:I I3). Evidence suggests that young infants start to point communicatively for two motives: to request things and to share emotions (Tomasello 2008: I I3). Tomasello distinguishes between two types of declaratives: (a) "declaratives as expressives" are those which the infant uses to share an attitude with an adult about a common referent and (b) "declaratives as informatives" which are used by the infant to provide the adult with information. And he cites experimental evidence that suggests that the first manifestation of cooperative pointing in infants starts with expressive pointing, which begins at about $\mathrm{I} 2$ months. Thus, Liszkowski et al. conducted a series of experiments to test the motivation for pointing in I2-month-old infants (Liszkowski et al. 2004). They introduced novel objects that would appear at some distance, and experimentally manipulated the adult's reaction, to test whether the infant's intention was to share their attitude (surprise, or interest in the novel object). The adults could react in one of four ways: (I) looking at the event without looking at the infant (Event Condition), (2) emoting positively toward the infant without looking at the event (Face Condition), (3) doing nothing (Ignore Condition) or, (4) alternating their gaze between the infant and the event while emoting positively (Joint Attention/Share Condition). The results showed that,

when the adult simply looked to the indicated referent while ignoring the infant (Event condition), or when the adult simply expressed positive emotions to the infant while ignoring the indicated referent (Face condition), infants were not satisfied. In comparison with the Joint Attention condition, in which infants typically gave one long point, infants in these 
conditions (as well as in the Ignore condition) tended to repeat their pointing gesture more often within trials - apparently as persistent attempts to establish shared attention and interest. Moreover, infants in these conditions (as well as in the Ignore condition) pointed less often across trials than in the Joint Attention condition - apparently indicating growing dissatisfaction with this adult as a communicative partner since she did not respond by sharing infants' attitude to the referent. (Tomasello 2008: I I9)

This and other experiments that show the pre-linguistic infants engaging in pointing in order to share their emotional attitudes with others are significant, as they show a capacity and motivation to engage in some sort of joint activity (in this case joint attention) prior to the development of linguistic development. Now one may ask why we should consider the sharing of emotions in joint attention as a form of joint cooperative activity. Now, Tomasello argues, rightly in my opinion, that "The sine qua non of collaborative action is a joint goal and a joint commitment among participants to pursue it together, with a mutual understanding among all that they share this joint goal and commitment" (Tomasello 2008: I 8I). And I take it that in the sharing of excitement with an infant about an object, the evidence suggests that there is a joint goal (namely to share the excitement) and a joint commitment, evidenced by the infants attempts to re-engage if the adult disengages. And it seems plausible to assume that the infant recognizes that the adult shares the goal. So, I think there is good reason to think that even the sharing of excitement about a new object with an infant counts as a simple form of joint collaborative activity.

There is also experimental evidence that I2-month-old infants also point declaratively to help adults by providing them with information they may need. These experiments involve adults searching for a misplaced object. And the results show that I 2-month-old infants often point to the object to help the adult with their search (Tomasello 2008:I2I). Tomasello argues that such behavior presupposes an understanding that others can have or lack information, plus an altruistic motive. I would add that such behavior shows the beginning of a capacity to recognize others as ends in themselves, who one can help in the pursuit of their own ends.

A further, morally relevant capacity is the capacity for role reversal. Young human infants are able to play games that involve distinct roles: such as a giver and a receiver. Once they have learnt the game having played one of the roles they are able to play the same game taking the other role. Such an ability involves the capacity to take a "birds eye" view of the activity and to recognize that there are different roles that different 
individuals can take. This capacity to understand that roles in an activity are fungible and can be played by different individuals is important for being able to see things from the perspective of others and is probably necessary for the capacity to decide whether a certain type of activity is universalizable. Once again there is some evidence to suggest that this capacity is unique to biological human beings. ${ }^{37}$

In terms of how this empirical research is related to Kant's ethics, I would suggest that the capacity to engage in helpful informative declaratives is related to the second formulation of the categorical imperative (the formulation of respect for humanity), for it shows the beginning of the capacity to recognize and incorporate the ends of others into one's own ends. The capacity to engage in expressive declaratives, with the intention to share attention, is related to the third formulation of the categorical imperative as it shows the capacity and desire for creating a "we." What is important to the infant is that we are looking at the object of interest together and sharing our emotions. And there is a normative element to this shared attention as the infant demands that we look and share the emotion, and is concerned to re-engage us if we do not share the moment. Although a I 2-month-old baby is clearly not capable of fully moral agency, I suggest that these two capacities show some form of moral agency. And organisms capable of such activities are demanding of some moral respect. I have suggested that rather than being a binary either-or matter, the capacity for moral agency comes in degrees, and if what is demanding of respect is the capacity for moral agency, then the sort of respect that is required is also something that comes in degrees depending on the type of moral agency of the organism concerned. If I am right, then someone who systematically refuses to engage with infants who are attempting, for example, to engage in sharing of emotions is failing to show respect for humanity.

\footnotetext{
"But in a series of simple cooperative tasks in which a human played one role and the chimpanzee a complementary role - for example, the human held out a plate and the chimpanzee placed a toy on it - when the human forced a role reversal chimpanzees basically either did not reverse roles, or else they performed their action without reference to the human. In a similar series of tasks, human infants not only reversed roles, but when they did so they looked expectantly to the adult in anticipation of her playing her new role in their shared task. . Our interpretation is that human infants understand joint activity from a 'bird's-eye view,' with the joint goal and complementary roles all in a single representational format - which enables them to reverse roles as needed. In contrast, chimpanzees understand their own action from a first-person perspective and that of the partner from a third-person perspective, but they do not have a bird's-eye view of the interaction and so there really are no roles, and so no sense in which they can reverse roles, in 'the same' activity" (Tomasello 2008:178-9).
} 
I have suggested that the work of Tomasello and his associates suggests that I 2-month-old babies are deserving of some degree of moral respect. And the work of Reddy and others suggests that the capacities that Tomasello thinks develop at around $\mathrm{I} 2$ months develop earlier in infancy. This raises the question of whether there are non-human animals that are deserving of some degree of moral respect (rather than mere compassion). Here I think the empirical evidence is inconclusive.

Many animals are territorial. And one question concerning our moral relationship to non-human animals has to do with whether we should respect their territories. There is often conflict between humans and nonhuman animals regarding territory. And such conflict is often the result of humans encroaching on the territory of non-human animals. ${ }^{38}$ There are many moral reasons to recognize and protect various animal species, and this may involve recognizing their territories. But there is a further question as to whether we should recolonize non-human animals as having some sort of property rights to their territories. Here, I believe the Kantian response would have to do with whether non-human animal species are capable of anything like mutual respect and have the capacity to recognize that they are sharing the land with us. And here the evidence is inconclusive. Many non-human animals are clearly able to recognize boundaries between, say, the forest and cultivated lands, and show behavior differences in terms of how they forage in cultivated land. So, for example, Sukumar points out that "Adult Asian elephant bulls are predominantly solitary during their daytime movements in the wild. I noticed, however, a distinct tendency among bulls to associate with each other while raiding crop fields at night" (Sukumar 2003:3017). This differential behavior clearly indicates that elephants recognize a difference between forest land and cultivated land. But such behavior may just be a result of learning about different risks involved in foraging in cultivated land. From the evidence I have examined it is unclear whether any non-human animals living in proximity to humans are able to mutually respect the territory of one another, and I think a Kantian should take this capacity as the basis for whether we should regard non-human animals as being subjects of property rights.

Also relevant is whether non-human animals are capable of altruistic behavior and whether they are able to treat others as ends rather than merely as means. Comparative research by Tomasello and his associates on the pointing capacities of human infants and chimpanzees suggests that

\footnotetext{
${ }^{8}$ See, for example, Chatterjee 2016, Leblan 2016, Sukumar 2003, chapter 2 and chapter 8.
} 
chimpanzees are able to interact with others, but only see others as social tools to be used, rather than ends in themselves. If this research is reliable, it would suggest that chimpanzees are not capable of relationships based on mutual respect. Thus, they claim that although chimpanzees do not point in the wild, chimpanzees who have had experience of contact with humans do learn to point imperatively. They point out, however, that,

Importantly though, they use this manual gesture imperatively only. That is, they point for humans either in order to obtain a desirable object from them directly ... or indirectly by requesting from the human to provide the necessary conditions for them to get the object themselves... It thus seems that what the apes have learned from their experience with humans is that the human will help them, and that they can use the pointing gesture instrumentally in order to make him help them. They thus "use" the human as a "social tool" in order to get things they otherwise could not get, and they have learned that pointing gets this tool to work... However, no ape has ever been observed to point for another ape or for a human declaratively - that is, just for the sake of sharing attention to some outside entity, or to inform others of things cooperatively, as humans often do. (Moll and Tomasello 2007:643)

Tomasello also argues that chimpanzees have very limited motivations for altruistic behavior. Indeed, he thinks that chimpanzees are fundamentally competitive and lack the motivation and the skills to engage in collaborative activity (Tomasello 2008:177). And he suggests that the development of altruistic, cooperative motivation was the first major development in the evolution of humanity away from the other apes. And other apes show very limited motivation to help others, especially in situations involving food. ${ }^{39}$

If Tomasello is right, this would suggest that although chimpanzees may be subjects of compassion, they are not objects of respect in the Kantian sense. However, Tomasello's research has been questioned by a number of prominent primatologists. One major criticism is methodological. Tomasello's research is primarily in the form of laboratory experiments, and some primatologists believe that in such unnatural settings the capacities they are interested in are less likely to manifest themselves, and that a more ethological approach is required. So, for example, de Waal has shown that chimpanzees in the wild show a pattern to share food in exchange for

39 Thus Tomasello argues that "chimpanzees sometimes help humans and one another. .. they do not help others in situations in which they themselves have a chance to obtain food - even when it would be easy for them to do so at no cost" (p.I84). For empirical support for these claims see: Silk et al. 2005; Jensen et al. 2006; and Warneken and Tomasello 2006 and 2007. 
grooming, which suggests some capacity for reciprocity, which De Waal labels reciprocal altruism (de Waal 1997). Such food sharing is, he argues, governed by turn-taking conventions and he even suggests that such sharing leads to some form of mutual obligation (de Waal 1989). And Sarah F. Brosnan and de Waal have even presented some evidence that capuchin monkeys have some sense of fairness (Brosnan and de Waal 2003). The interpretation of the experiments that claim to show a concern for fairness among monkeys has, however, been questioned by Tomasello and his research group. ${ }^{40}$

The empirical research, then, on whether or not there are non-human animals that have some sort of moral capacities is inconclusive. And there is, on the account I have offered, no criterion or principle we can apply to determine who we are capable of engaging in joint cooperative activities with; the only way of finding this out is by trying, and for us to have an openness to the invitations being made to us by the world around us. To recognize that another bit of the phenomenal world is "human" in the morally relevant sense is not to categorize that part of the world by applying a concept that has necessary and sufficient conditions of application, but to pick up on the possibility of a certain type of interaction. The fact that we have not succeeded in engaging in joint cooperative activities with non-human nature does not mean that such activities are impossible. It might just mean that we have not tried hard enough. And the empirical research on this issue is inconclusive.

In terms of how we go about recognizing morally relevant others, I believe that the best answer to this question is most likely to be provided by psychologists like Tomasello who are trying to understand the psychological basis and development of our capacity to engage in joint cooperative activities. ${ }^{4 \mathrm{I}}$

$4^{\circ}$ Bräuer, Call, and Tomasello 2006 and 2009.

${ }^{4}$ S Support for work on this chapter was provided by Boğaziçi -Southampton Newton-Katip Çelebi project AFI 4007I, Bogazici University BAP project 9320 and Tubitak Project I I 4k348 "Concepts and Belief: From Perception to Action." I would like to thank the following people for comments on previous drafts: Paul Guyer, Ken Westphal, Zübeyde Karadağ, Martin Sticker, Gözde Yıldırım, Sasha Mudd, Merve Tapinc, Hakkı Kaan Arıkan, Taylan Susam and Bill Wringe. 